\title{
Gray Ramus Communicans Nerve Block for Acute Pain Control in Vertebral Compression Fracture
}

\author{
Dou-Young Park ${ }^{1} \oplus$, Il Choi ${ }^{1, *}$ ) , Tae-Gyum Kim ${ }^{2}$, Woo-Jae Kim ${ }^{3}$, Il-Young Shin ${ }^{1}$ and Eun-Kyung Khil ${ }^{4}(\mathbb{C}$ \\ 1 Department of Neurological Surgery, Dongtan Sacred Heart Hospital, Hallym University Hwaseong, \\ Hwaseong 18450, Korea; Dypark1016@gmail.com (D.-Y.P.); kosaken@hallym.or.kr (I.-Y.S.) \\ 2 Department of Neurosurgery, Ace Hospital, Ansan 39177, Korea; kimtk0311@hallym.or.kr \\ 3 Department of Neurosurgery, Youngdong Hospital, Hwaseong 38611, Korea; mediboy1@hallym.or.kr \\ 4 Department of Radiology, Dongtan Sacred Heart Hospital, Hallym Unverisity, Hwaseong 18450, Korea; \\ nizzinim@gmail.com \\ * Correspondence: heycai79@gmail.com; Tel.: +82-10-5310-6274; Fax: +82-31-8086-2410
}

check for updates

Citation: Park, D.-Y.; Choi, I.; Kim,

T.-G.; Kim, W.-J.; Shin, I.-Y.; Khil, E.-K. Gray Ramus Communicans Nerve Block for Acute Pain Control in Vertebral Compression Fracture. Medicina 2021, 57, 744. https:// doi.org/10.3390/medicina57080744

Academic Editor: Jose Antonio de Paz

Received: 5 June 2021

Accepted: 21 July 2021

Published: 23 July 2021

Publisher's Note: MDPI stays neutral with regard to jurisdictional claims in published maps and institutional affiliations.

Copyright: (c) 2021 by the authors. Licensee MDPI, Basel, Switzerland. This article is an open access article distributed under the terms and conditions of the Creative Commons Attribution (CC BY) license (https:/ / creativecommons.org/licenses/by/ $4.0 /)$.

\begin{abstract}
Background and Objectives: The current options for acute pain control of vertebral compression fracture include hard brace, vertebroplasty, early surgery, and analgesic injection. We hypothesize that the gray ramus communicans nerve block (GRNB) controls the acute pain experienced during vertebral compression fractures. This study assessed the time course of pain control after injection and evaluated the risk factors affecting pain control failure. Materials and methods: Sixty-three patients ( 24 male, $66.19 \pm 15.17 \mathrm{y}$ ) with a thoracolumbar vertebral fracture at the T10-L5 spine, who presented to our hospital from November 2018 to October 2019, were included in this retrospective cohort study. GRNB was performed within 1 week of the trauma. The patients were followed up on days 3, 14, 30, 90, and 180 and assessed with the serial visual analog scale (VAS, resting and motion), Oswestry Low Back Disability (ODI) questionnaire, and Roland-Morris Disability Questionnaire (RDQ). The failure group was defined by the need for an additional block or cement injection after a single GRNB. The failure group's risk factors, such as body mass index, initial thoracolumbar injury classification and severity score, Kummel's disease, age, bone marrow density (BMD), and underlying disease, were analyzed. Results: The motion VAS score improved from preoperative to three months post-procedure, but the resting VAS was affected by the procedure for only three days. The quality of life index improved at postoperative six months. A lower BMD was the only risk that affected treatment failure in the logistic regression analysis $(p=0.0038)$. Conclusion: The effect of GRNB was maintained even at three months after trauma based on motion VAS results. The only risk factor identified for GRNB failure was lower BMD.
\end{abstract}

Keywords: osteoporosis; compression fracture; bone marrow density; serial visual analog scale; Oswestry Low Back Disability Questionnaire; Roland-Morris Disability Questionnaire

\section{Introduction}

As we have entered an aging society, osteoporotic vertebral fractures are on the rise, and the number of patients with traumatic vertebral fractures is increasing [1]. The prevalence of osteoporosis has been reported as $40-90 \%$ in women $>50$ years. Spinal compression fracture is the most common complication, and a $12-40 \%$ prevalence of osteoporotic compression fractures has been reported among individuals $>50$ years [2-4]. Most vertebral fractures heal naturally over time, and the pain is relieved. However, in some patients, especially in the elderly patient group, many patients suffer from intolerable pain, neurologic deficits, and, rarely, deformities, which lead to a decreased quality of life. The patients with spine fractures suffered from pain which prolongs hospitalization and increases the bed rest period. Therefore, the pain interventions that effectively manage pain and shorten recovery time would be of great benefit $[5,6]$. Several papers have demonstrated that vertebroplasty or kyphoplasty effectively relieves pain in patients with 
osteoporotic vertebral fracture [6-9]. As an alternative, there have been studies on gray ramus nerve block (GRNB), which has been shown to affect pain relief [10-14]. However, there has been no study on how long the effect of gray ramus nerve block was maintained and what patient characteristic impacts its duration. Therefore, we designed this study to confirm that the GNRB effectively reduces pain in patients with vertebral body fractures and to analyze the cause of treatment failure in the ineffective group.

The primary goal of this study was to analyze the time course of pain control after GNRB. Secondary goals were to evaluate the risk factors for failing pain control after GNRB. We defined 'pain control failure' as requiring additional procedures such as a repeated block or vertebroplasty or kyphoplasty.

\section{Materials and Methods}

\subsection{Study Design, Setting, and Patient Population}

The Institutional Review Board at Hallym University reviewed and approved this retrospective study. We found spinal fracture patients admitted to the neurosurgery department between 1 November 2018 and 1 November 2019 through electronic medical record (EMR) system. As inclusion criteria, patients had an index thoracolumbar fracture from T10 to L5, adult patients over 18 years of age were included, and patients who underwent computed tomography (CT)or magnetic resonance imaging (MRI) for fracture evaluation were included. The exclusion criteria were as follows: visual analog scale (VAS) score was 3 or less; no acute fracture on CT or MRI; spine fracture which needs fixation surgery; spine fractures other than T10-L5 fractures; multiple trauma combined T10-L5 fractures; pathologic fractures such as tumor, infection, etc.; severe soft tissue injury such as multiple burn injuries (Figure 1).

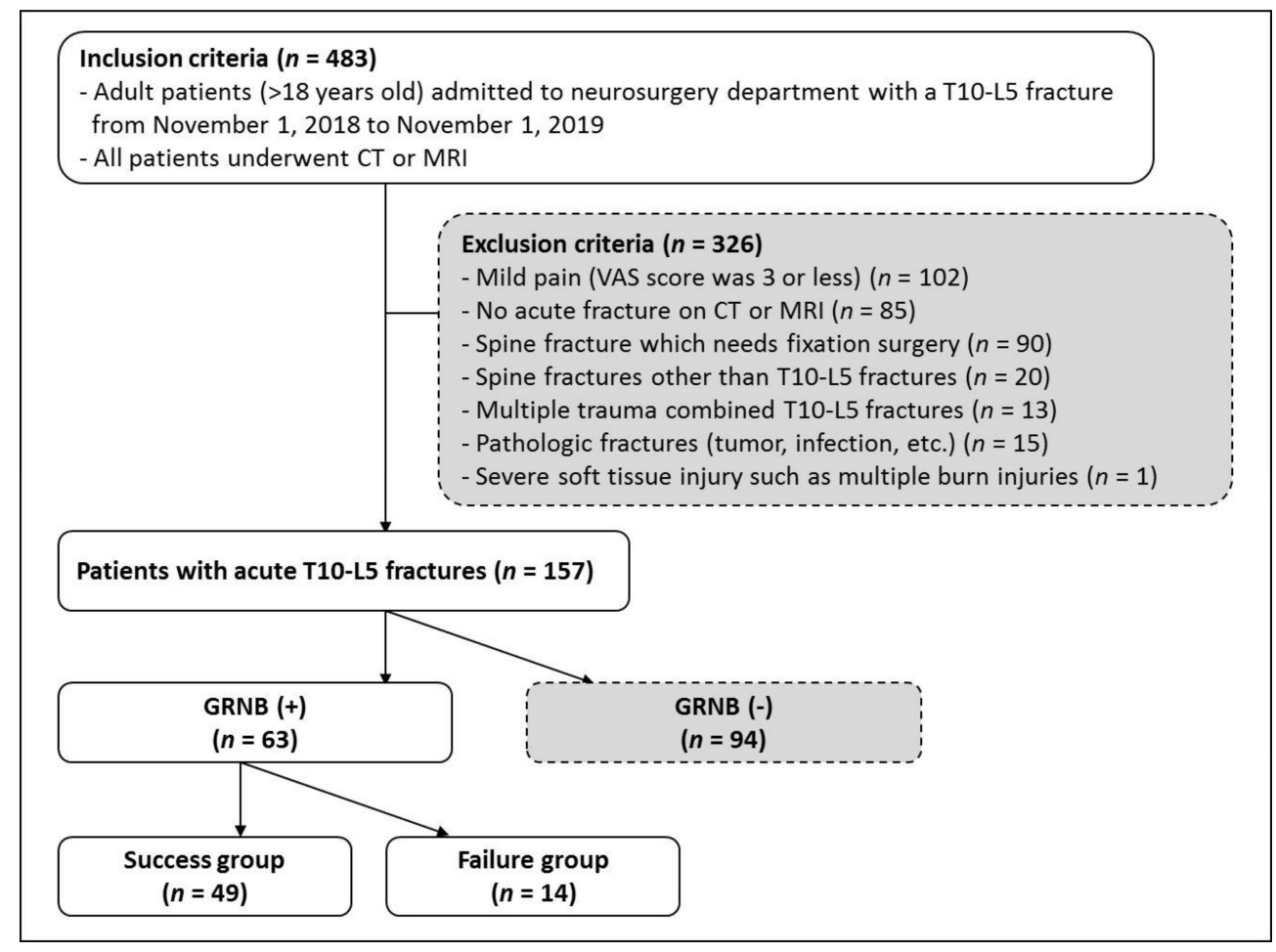

Figure 1. Flow chart of numbers of participants at each stage of study divided into a success group and a failure group. Computer Tomography (CT); Magnetic resonance imaging (MRI); visual analog scale (VAS); gray ramus communicans nerve block (GRNB).

For all patients, thoraco-lumbo-sacral orthosis braces were worn, and conservative treatment for pain relief was started. Oral tapentadol $50 \mathrm{mg}$ was taken twice a day for 7 days, then tramadol $37.5 \mathrm{mg}+$ acetaminophen $325 \mathrm{mg}$ combination was prescribed twice a day. To patients who did not improve their pain with oral mediation, additional 
intravenous analgesics were given such as ketorolac $30 \mathrm{mg}$ or tramadol $50 \mathrm{mg}$. Additionally, osteoporosis was evaluated and treated. Within three days after trauma, GRNB was performed under fluoroscopy under local anesthesia.

The sex, age, body mass index (BMI), bone marrow density (BMD), underlying disease, and medications, such as steroids, were analyzed in all patients.

\subsection{Gray Ramus Nerve Block}

The procedure was performed in a biplane angiography room. Patients were placed in a prone position with a soft bed table and arms hanging over the table. Under the fluoroscopic images, a 23 gauge spinal needle was laterally inserted toward the center of the fractured vertebral body. Approximately $3.5 \sim 5.0 \mathrm{~cm}$ from the midline of the vertebral body just inferior to the transverse process, usually $1.5 \sim 2.0 \mathrm{~cm}$ lateral to the inferior endplate in case of the thoracic region. The needle was then advanced through just inferior to the pedicle and advanced into a slightly anterosuperior aspect of the foramen. The needle tip was positioned approximately 5-10 $\mathrm{mm}$ anterior to the foramen and just above the foramen roof, where the most proximal portion of gray ramus communicans is known to be located [15]. After grossly confirming that the needle was where we wanted it, the correct position was then confirmed radiographically with an injection of $0.5 \mathrm{cc}$ of contrast dye injection (Bonorex). We then injected a combination of 2 cc lidocaine, $5 \mathrm{mg}$ of dexamethasone, and 2 cc of normal saline on each side of the gray ramus communicans of the fractured vertebral body (Figure 2).

(A)

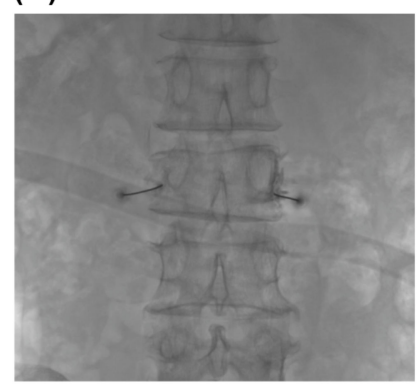

(B)

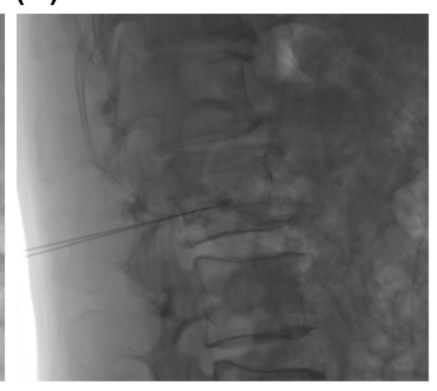

Figure 2. Gray ramus communicans nerve block procedures under the fluoroscopy. Anteroposterior (A) and lateral (B) fluoroscopic pictures show that it was confirmed through contrast media and images that the tip of the spinal needle is at the position of the gray ramus communicans.

During the nerve block procedure, the patient's vital signs were checked, and after the procedure, we monitored for any signs of complications. (Figures 2 and 3).

\subsection{Outcome Assessment and Evaluation of Risk Factors for Pain Control Failure}

The same questionnaire was administered to all fracture patients, such as VAS (divided into motion and resting score) for pain intensity and characteristics. The Oswestry Low Back Disability (ODI) and Roland-Morris Disability Questionnaire (RDQ) assessments for quality of life were analyzed pre-procedure and at three days, 14 days, 30 days, 90 days, and 180 days post-procedure. The dose of analgesics was monitored for their effect of GRNB before and after the procedure.

The patients were divided into two groups: success and failure groups. We defined 'treatment failure' as either the absence of pain improvement or the need for another procedure, such as repeat GRNB or vertebroplasty. Sex, age, smoke, alcoholics, bone marrow density (BMD), BMI, Kummel's disease, thoracolumbar injury classification and severity score (TLICS), underlying illnesses (e.g., hypertension, diabetics), and medications (e.g., steroids) were analyzed as risk factors of GRNB failure. 


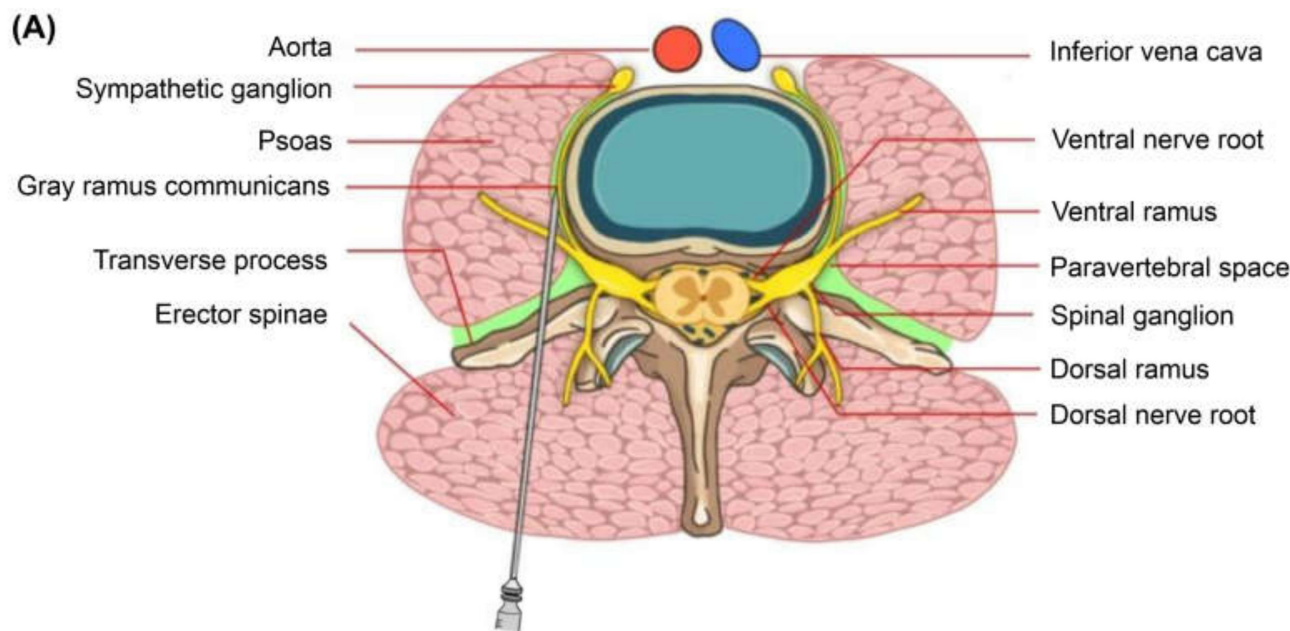

(B)

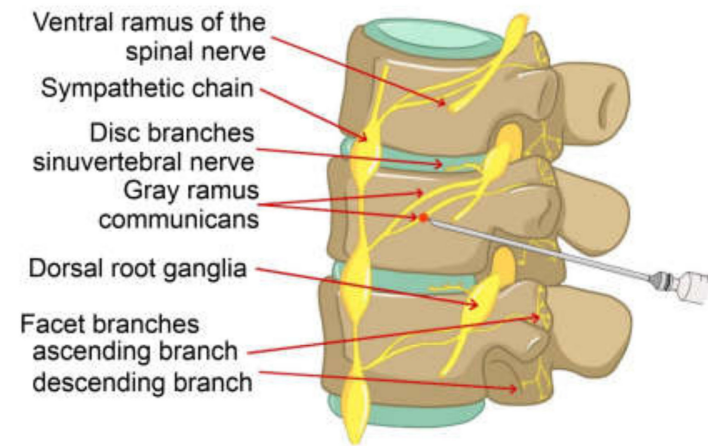

(C)

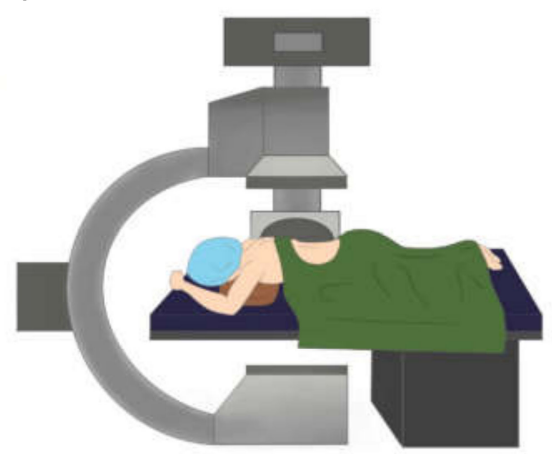

Figure 3. Illustration of gray ramus nerve block procedure: (A) axial view, (B) sagittal view, (C) the setting and position of patient and fluoroscopy for gray ramus communicans nerve block.

\subsection{Statistical Analysis}

Data were analyzed using SPSS (version 20.1, SPSS Inc. Chicago, IL, USA). The primary outcome measures were changes in the VAS, ODI, and RDQ scales over time as determined by using a repeated measure ANOVA. The model included the pattern of covariance between repeated observations to account for correlations between observations within each patient. For the secondary outcome analysis, unpaired Student t-tests or MannWhitney tests were used for continuous variables, and chi-square tests or Fisher's exact test was used for categorical variables. The following baseline characteristics of patients experiencing treatment failure after GRNB were examined for statistically significant differences: The sex, age, BMI, BMD, underlying disease, and medications, such as steroids.

\section{Results}

\subsection{Participants}

Of the 483 patients with vertebral fracture during that period, 94 patients declined the procedure, and 312 patients were excluded due to mild pain of VAS score 3 or less, no acute fractures, or pathological fractures. Finally, 63 patients underwent the gray ramus nerve block procedure (Figure 1).

The characteristics of the 63 study patients are summarized in Table 1. Twenty-four patients were men $(24 / 63,38 \%)$ with a mean age of 66.19 years $( \pm 15.95$, standard deviation, SD). Forty-three patients had a job (68\%), and $21(33 \%)$ had graduated from college. Seven patients $(11 \%)$ were smokers, and 16 patients $(25 \%)$ were alcoholics. Twenty-seven patients $(43 \%)$ were diagnosed with hypertension and eight patients $(13 \%)$ had diabetes mellitus. Two patients ( $3 \%$ ) had Kummel's disease. Their BMIs were overweight (24.06 \pm 3.84$)$, and BMD was in a decreased state $(-2.12 \pm 1.37)$. The TLICS results $(2.81 \pm 1.47)$ indicate that conservative treatment was recommended. 
Table 1. Demographic and clinical characteristics of the study patients (number $=63$ ).

\begin{tabular}{|c|c|c|c|c|c|c|c|}
\hline \multirow[b]{2}{*}{ Gender (male) } & \multicolumn{2}{|c|}{$\begin{array}{c}\text { Total } \\
n=63\end{array}$} & \multicolumn{2}{|c|}{$\begin{array}{l}\text { Failure Group } \\
\qquad n=14\end{array}$} & \multicolumn{2}{|c|}{$\begin{array}{c}\text { Success Group } \\
n=49\end{array}$} & \multirow{2}{*}{$\frac{p \text {-Value }}{0.1454}$} \\
\hline & 24 & $38 \%$ & 3 & $21 \%$ & 21 & $43 \%$ & \\
\hline Age & 66.19 & 15.17 & 72.86 & 7.77 & 64.29 & 16.41 & 0.0088 \\
\hline Job, yes & 20 & $31 \%$ & 1 & $7 \%$ & 19 & $39 \%$ & 0.0267 \\
\hline Post-secondary education & 21 & $33 \%$ & 2 & $14 \%$ & 19 & $39 \%$ & 0.0879 \\
\hline Smoke, yes & 7 & $11 \%$ & 1 & $7 \%$ & 6 & $12 \%$ & 1.0000 \\
\hline Alcoholism, yes & 16 & $25 \%$ & 3 & $21 \%$ & 13 & $26 \%$ & 0.6989 \\
\hline HTN & 27 & $42 \%$ & 8 & $57 \%$ & 19 & $39 \%$ & 0.2207 \\
\hline $\mathrm{DM}$ & 8 & $13 \%$ & 1 & $7 \%$ & 7 & $14 \%$ & 0.6714 \\
\hline Kummell & 2 & $3 \%$ & 0 & $0 \%$ & 2 & $4 \%$ & 1.0000 \\
\hline BMI & 24.06 & 3.61 & 23.64 & 2.26 & 24.18 & 3.95 & 0.5275 \\
\hline BMD & -2.12 & 1.42 & -3.31 & 0.93 & -1.79 & 1.38 & 0.0003 \\
\hline Duration to GRNB after fracture, days & 4.6 & 4.15 & 4.79 & 2.81 & 4.55 & 4.51 & 0.8559 \\
\hline Back pain duration, days & 4.04 & 4.33 & 3.64 & 3.15 & 4.16 & 4.66 & 0.6976 \\
\hline TLICS & 2.92 & 3.15 & 3.29 & 3.28 & 2.82 & 1.48 & 0.2932 \\
\hline
\end{tabular}

HTN: hypertension, DM: diabetes mellitus, BMI: body mass index, BMD: bone marrow density, GRNB: gray ramus nerve block. TLICS: thoraco-lumbar injury classification and severity score.

There were three male and 11 female patients in the treatment failure group. There were 21 male and 28 female patients in the treatment success group. There were no significant differences in education, job, or BMI between the success and failure groups. The TLICS score showed no significant difference between the treatment failure and success groups ( 3.29 vs. 2.82). There were no significant differences between the two groups, with an average duration of 5 days after fracture. The treatment failure group's average age was 72.86 years, which was higher than the average age of the treatment success group, 64.26 years $(p=0.0088)$. The treatment failure group's average BMD was -3.31 , which was lower than the average BMD of the treatment success group $(-1.79, p=0.0003)$ (Table 1$)$.

\subsection{The Changes in Pain and Functional Outcome Overtime after GRNB}

Pre-procedure motion VAS was $7.88 \pm 0.31$. After the procedure, the pain score was serially improved at 3 days $(4.94 \pm 0.36, p<0.0001), 14$ days $(4.06 \pm 0.35, p<0.0001)$, 30 days $(2.86 \pm 0.29, p<0.0001), 90$ days $(2.39 \pm 0.28, p<0.0001)$. After 90 days, the pain score change did not differ significantly at 180 days $(0.27 \pm 0.19)$. The pattern of resting VAS change was different from that of motion VAS. The resting VAS score was $4.37 \pm 0.38$. Symptom improvement was seen at three days $(2.27 \pm 0.32, p<0.0001)$, but was then unremarkable at 14 days $(1.73 \pm 0.29, p=0.24), 30$ days $(1.24 \pm 0.21, p=0.05), 90$ days $(1.24 \pm 0.19, p>0.99)$ and 180 days $(1.06 \pm 0.22, p=0.14)$.

The life quality index, ODI, and RDQ showed improvement over 6 months for all participants. The ODI was improved from pre-procedure $(77.95 \% \pm 18.28$, standard deviation) to 3 day $(60.80 \% \pm 18.65 \%, p=<0.0001), 14$ days $(48.41 \% \pm 21.10 \%, p=<0.0001)$, 30 days $(40.37 \% \pm 20.27 \%, p=0.00)$, 90 days $(32.49 \% \pm 22.82 \%, p=0.00)$ and 180 days $(22.73 \% \pm 16.08 \%, p<0.0001)$. The initial RDQ, a life quality index, was $19.59 \pm 3.57$ and improved at 3 days $(18.24 \pm 3.70, p=0.05), 14$ days $(15.59 \pm 4.34, p=0.00), 30$ days $(13.35 \pm 5.06, p<0.0001), 90$ days $(10.69 \pm 5.92, p<0.0001)$, and 180 days $(9.18 \pm 5.45$, $p=0.00$ ) over 6 months (Tables 2 and 3 ). 
Table 2. Changes in outcome scales over time after the procedure and comparison of outcome scales at each time point after treatment.

\begin{tabular}{|c|c|c|c|c|c|c|c|c|c|c|c|c|c|c|c|c|}
\hline \multirow[b]{2}{*}{ Time } & \multicolumn{4}{|c|}{ VAS $n=49$} & \multicolumn{4}{|c|}{ VAS at Rest $n=49$} & \multicolumn{4}{|c|}{ ODI $n=49$} & \multicolumn{4}{|c|}{ RDQ $n=49$} \\
\hline & Mean & $\mathrm{SE}$ & $p$-Value ${ }^{\text {a }}$ & $p$-Value ${ }^{\mathrm{b}}$ & Mean & SE & $p$-Value ${ }^{\text {a }}$ & $p$-Value ${ }^{\mathrm{b}}$ & Mean & SE & $p$-Value ${ }^{a}$ & $p$-Value ${ }^{\mathrm{b}}$ & Mean & $\mathrm{SE}$ & $p$-Value ${ }^{\mathrm{a}}$ & $p$-Value ${ }^{\mathrm{b}}$ \\
\hline 0 & 7.88 & 0.31 & $<0.0001$ & & 4.37 & 0.38 & $<0.0001$ & & $77.95 \%$ & $18.28 \%$ & $<0.0001$ & & 19.59 & 3.57 & $<0.0001$ & \\
\hline 3 & 4.94 & 0.36 & & & 2.27 & 0.32 & & & $60.80 \%$ & $18.65 \%$ & & & 18.24 & 3.70 & & \\
\hline 30 & 2.86 & 0.29 & & & 1.24 & 0.21 & & & $40.37 \%$ & $20.27 \%$ & & & 13.35 & 5.06 & & \\
\hline 90 & 2.39 & 0.28 & & & 1.24 & 0.19 & & & $32.49 \%$ & $22.82 \%$ & & & 10.69 & 5.92 & & \\
\hline 180 & 2.12 & 0.31 & & & 1.06 & 0.22 & & & $22.73 \%$ & $16.08 \%$ & & & 9.18 & 5.45 & & \\
\hline diff 3 vs. 0 & 2.94 & 0.38 & & $<0.0001$ & 2.10 & 0.40 & & $<0.0001$ & $17.15 \%$ & 2.58 & & $<0.0001$ & 1.35 & 0.68 & & 0.05 \\
\hline diff 30 vs. 0 & 5.02 & 0.41 & & $<0.0001$ & 3.12 & 0.42 & & $<0.0001$ & $37.58 \%$ & 3.98 & & $<0.0001$ & 6.25 & 0.84 & & $<0.0001$ \\
\hline diff 90 vs. 0 & 5.49 & 0.42 & & $<0.0001$ & 3.12 & 0.43 & & $<0.0001$ & $45.46 \%$ & 4.23 & & $<0.0001$ & 8.90 & 0.91 & & $<0.0001$ \\
\hline diff 180 vs. 0 & 5.76 & 0.44 & & $<0.0001$ & 3.31 & 0.45 & & $<0.0001$ & $55.21 \%$ & 3.46 & & $<0.0001$ & 10.41 & 0.87 & & $<0.0001$ \\
\hline diff 14 vs. 3 & 0.88 & 0.42 & & 0.041 & 0.53 & 0.45 & & 0.24 & $12.39 \%$ & 3.27 & & $<0.0001$ & 2.65 & 0.73 & & 0.00 \\
\hline diff 30 vs. 3 & 2.08 & 0.40 & & $<0.0001$ & 1.02 & 0.40 & & 0.01 & $20.43 \%$ & 3.29 & & $<0.0001$ & 4.90 & 0.81 & & $<0.0001$ \\
\hline diff 90 vs. 3 & 2.55 & 0.42 & & $<0.0001$ & 1.02 & 0.34 & & 0.00 & $28.31 \%$ & 3.51 & & $<0.0001$ & 7.55 & 0.96 & & $<0.0001$ \\
\hline diff 180 vs. 3 & 2.82 & 0.46 & & $<0.0001$ & 1.20 & 0.37 & & 0.00 & $38.06 \%$ & 2.99 & & $<0.0001$ & 9.06 & 0.92 & & $<0.0001$ \\
\hline diff 30 vs. 14 & 1.20 & 0.27 & & $<0.0001$ & 0.49 & 0.25 & & 0.05 & $8.04 \%$ & 2.62 & & 0.00 & 2.25 & 0.58 & & $<0.0001$ \\
\hline diff 90 vs.14 & 1.67 & 0.28 & & $<0.0001$ & 0.49 & 0.29 & & 0.10 & $15.92 \%$ & 2.59 & & $<0.0001$ & 4.90 & 0.69 & & $<0.0001$ \\
\hline diff 180 vs. 14 & 1.94 & 0.35 & & $<0.0001$ & 0.67 & 0.32 & & 0.04 & $25.67 \%$ & 2.56 & & $<0.0001$ & 6.41 & 0.72 & & $<0.0001$ \\
\hline diff 90 vs. 30 & 0.47 & 0.20 & & 0.02 & 0.00 & 0.15 & & 1.00 & $7.88 \%$ & 2.41 & & 0.00 & 2.65 & 0.53 & & $<0.0001$ \\
\hline diff 180 vs. 90 & 0.27 & 0.19 & & 0.17 & 0.18 & 0.12 & & 0.14 & $9.76 \%$ & 2.19 & & $<0.0001$ & 1.51 & 0.44 & & 0.00 \\
\hline
\end{tabular}

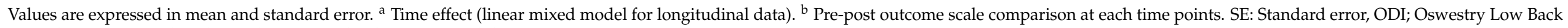

Disability, VAS: visual analog scale, RDQ: Roland-Morris Disability Questionnaire. 
Table 3. Risk factors analysis for pain control failure after gray ramus nerve block

\begin{tabular}{|c|c|c|c|c|c|c|c|c|c|c|c|c|c|}
\hline \multirow{2}{*}{ Gender } & \multirow{2}{*}{$\mathrm{M}$} & & & & & \multicolumn{4}{|c|}{$\begin{array}{l}\text { Univariate Model } \\
\quad 95 \% \mathrm{CI}\end{array}$} & \multicolumn{4}{|c|}{$\begin{array}{c}\text { Multivariate Model + Variable Selection } \\
\text { 95\% CI }\end{array}$} \\
\hline & & \multicolumn{2}{|c|}{$\begin{array}{c}\text { Failure Group } \\
\quad n=14\end{array}$} & \multicolumn{2}{|c|}{$\begin{array}{l}\text { Success Group } \\
\quad n=49\end{array}$} & $\begin{array}{l}\text { OR } \\
2.75\end{array}$ & $\begin{array}{c}\text { Lower } \\
0.68\end{array}$ & $\begin{array}{c}\text { Upper } \\
11.11\end{array}$ & $\begin{array}{c}p \text {-Value } \\
0.1556\end{array}$ & OR & Lower & Upper & $p$-Value \\
\hline \multirow{3}{*}{ Smoke } & $\mathrm{F}$ & 11 & 21.43 & 28 & 42.86 & & & & & & & & \\
\hline & No & 13 & 92.86 & 43 & 87.76 & & & & & & & & \\
\hline & Yes & 1 & 7.14 & 6 & 12.24 & 1.81 & 0.20 & 16.47 & 0.5967 & & & & \\
\hline Alcoholism & No & 11 & 78.57 & 36 & 73.47 & & & & & & & & \\
\hline HTN & Yes & 8 & 57.14 & 19 & 38.78 & 0.48 & 0.14 & 1.58 & 0.2257 & & & & \\
\hline $\mathrm{DM}$ & Yes & 1 & 7.14 & 7 & 14.29 & 2.17 & 0.24 & 19.28 & 0.4881 & & & & \\
\hline History of osteoporosis & Yes & 2 & 14.29 & 3 & 6.12 & 0.39 & 0.06 & 2.61 & 0.3328 & & & & \\
\hline Steroid use & Yes & 0 & 0.00 & 0 & 0.00 & & & & - & & & & \\
\hline Kummell & Yes & 0 & 0.00 & 2 & 4.08 & 1.53 & 0.04 & 66.01 & 0.8256 & & & & \\
\hline Age & & 72.86 & 7.77 & 64.29 & 16.41 & 0.96 & 0.91 & 1.00 & 0.0721 & 0.97 & 0.94 & 1.01 & 0.0972 \\
\hline BMI & & 23.64 & 2.35 & 24.18 & 3.95 & 1.04 & 0.88 & 1.24 & 0.6243 & & & & \\
\hline BMD & & -3.31 & 0.97 & -1.79 & 1.38 & 2.80 & 1.46 & 5.39 & 0.0020 & 2.67 & 1.37 & 5.18 & 0.0038 \\
\hline TLICS & & 3.29 & 1.38 & 2.82 & 1.48 & 0.81 & 0.54 & 1.20 & 0.2907 & & & & \\
\hline
\end{tabular}

HTN: hypertension, DM, diabetes mellitus, BMI: body mass index, BMD, bone marrow density, TLICS: thoracolumbar injury classification and severity score. 
The frequency of analgesic injection use during hospitalization decreased in the GRNB treatment group. The average number of analgesic administrations decreased from 1.571 pre-GRNB to 0.265 post-GRNB in the success group. However, comparing to failure group, the number of analgesic injections was not significant different $(p=0.267)$.

\subsection{Risk Factor Analysis}

The failure group's risk factors, such as body mass index, initial thoracolumbar injury classification and severity score, Kummel's disease, age, bone marrow density (BMD), and underlying disease, were analyzed.

The mean age in the treatment success group was 64.29 years and 72.86 years in the treatment failure group $(p=0.0088)$. The average BMD of the treatment success group was -1.79 , which was significantly different from the treatment failure group $(-3.31)$. $(p=0.0003)$. Using a logistic regression model, BMD was a significant risk factor for treatment failure (Table 3).

\section{Discussion}

We report two key results from our study. The first is the time course of pain relief after GRNB. To date, there is no description of a clear change in pain improvement in the literature. In our study, the efficacy of GRNB was illustrated in motion VAS. The improvement started from 3 days immediately after the procedure and lasted until 90 days, with diminishing returns by 180 days. On the other hand, resting VAS was indicative on the 3rd day immediately after the procedure but did not show any significant difference over time. This finding means that GRNB is effective immediately after the procedure, and is more effective in pain caused by movement. Therefore, GNRB may enable earlier walking in fracture patients after the procedure, thereby reducing complications, such as pneumonia and thromboembolic events due to bed rest.

Several papers have demonstrated that GRNB was effective in pain relief in patients with vertebral fractures. In 2001, Chandler et al. in 52 osteoporotic vertebral fracture patients, GRNB after conservative treatment failure was administered with $2 \%$ lidocaine and $2 \%$ triamcinolone, which was different than the drugs used in our study. During an average follow-up period of 9 months, they observed an improvement in pain in $92 \%$ of patients. In $42 \%$ of patients, the demand for pain medication decreased, $50 \%$ reported high satisfaction, and 25\% had moderate satisfaction [12,16]. The change in treatment effect over time and the risk factor of the treatment failure group were not analyzed. Tae et al. showed improvement in pain in $94 \%$ of the treatment results for chronic osteoporotic compression fractures which failed in conservative treatment for 4 weeks and the pain relief lasted for four months [15]. In contrast, our study targeted patients with acute vertebral fractures within 3 days after fracture.

In our research, satisfactory pain improvement over three months, without additional treatments, was confirmed in $78 \%$ of patients. These were similar results to the study on GRNB in another study, Choi et al [17]. In another study by Kim et al., Radiofrequency (RF) was performed for pain relief in 22 patients with acute vertebral fractures, $48 \mathrm{~h}$ after the procedure. The reported pain improved rapidly, and the effect lasted up to 3 months at follow-up, similar to our results [10]. We summarized our result comparing with reference (Table 4) The second finding is that the GRNB effect decreased in the osteoporotic patients. When analyzing the clinical factors in the treatment failure group, there was a significant difference in BMD from the treatment success group $(-3.31$ in failure versus -1.79 in success, $p=0.0038)$. We think that in osteoporotic vertebral fracture patients, the vertebral body's stability was decreased, leading to persistent and longtime back pain after the injection. In previous GRNB-related papers, no risk analysis was performed for the patient group with a low treatment effect. 
Table 4. Summarization of our study comparing with References.

\begin{tabular}{|c|c|c|c|c|c|c|c|c|}
\hline & Number & Patient & $\begin{array}{l}\text { Intervention } \\
\text { Regimen }\end{array}$ & Intervention & Control & Outcome & $\begin{array}{l}\text { Follow Up } \\
\text { Period }\end{array}$ & Complication \\
\hline Our study & 63 & $\begin{array}{c}\text { acute } \\
\text { fracture, } \\
\text { within } 3 \mathrm{~d} \\
\text { after fracture } \\
\text { (T10 L5) }\end{array}$ & $\begin{array}{l}2 \% \text { bupivacaine } \\
5 \mathrm{mg} \\
\text { Dexamethasone }\end{array}$ & GNRB & None & $\begin{array}{c}\text { VAS, motion } \\
7.88 \text { at pre } \\
4.93 \text { at } 3 \text { days } \\
4.61 \text { at } 14 \text { days } \\
2.857 \text { at } 90 \text { day } \\
\text { sResting VAS } \\
\text { ODI } \\
\text { RDQ }\end{array}$ & $\begin{array}{c}\text { Before } \\
\text { And after } \\
3,14,30,90 \\
180 \text { days }\end{array}$ & $\begin{array}{l}\text { No infection } \\
\text { No vessel leak }\end{array}$ \\
\hline $\begin{array}{l}\text { Chandler } \\
2001[12]\end{array}$ & 52 & $\begin{array}{c}\text { After } \\
\text { conservative } \\
\text { analgesic } \\
\text { therapy } \\
\text { (TL) }\end{array}$ & $\begin{array}{c}2 \% \text { lidocaine } \\
2 \% \text { triamcinolone }\end{array}$ & GNRB & None & $\begin{array}{c}\text { VAS } 10 \\
92 \% \text { at least } 1 \\
63 \% \text { at least } 4\end{array}$ & $\begin{array}{l}\text { Before } \\
\text { And after }\end{array}$ & No report \\
\hline $\begin{array}{l}\text { SW kim } \\
2007[10]\end{array}$ & 22 & $\begin{array}{l}\text { less } 2 \text { weeks } \\
\text { after trauma } \\
\quad(\mathrm{L} 1-4)\end{array}$ & RF & $\mathrm{RF}$ & None & $\begin{array}{c}\text { VAS } \\
7.8 \text { at pre } \\
2.6 \text { at } 48 \mathrm{~h} \\
2.8 \text { at } 90 \mathrm{~d} \\
(p<0.005) \\
\text { Modified Macnab } \\
12-6-2-2 \\
\text { at E-G-F-P }\end{array}$ & $\begin{array}{l}\text { At least, } 4 \\
\text { month }\end{array}$ & $\begin{array}{l}\text { No significant } \\
\text { complication }\end{array}$ \\
\hline $\begin{array}{l}\text { HS Tae } \\
2003 \text { [15] }\end{array}$ & 36 & $\begin{array}{l}\text { after failure } \\
\text { conservative } \\
\text { treatment for } \\
4 \text { weeks or } \\
\text { vertebro- } \\
\text { plasty }\end{array}$ & $\begin{array}{l}\text { 2\% lidocaine } \\
5 \mathrm{mg} \\
\text { Dexamethasone } \\
40 \mathrm{mg} \text { Methyl- } \\
\text { prednisolone } \\
\text { acetate }\end{array}$ & GNRB & None & $\begin{array}{c}\text { VAS } \\
9.2 \text { at pre } \\
0 \sim 3(80.5 \%), 4 \sim 6 \\
(13,9 \%) \\
6<(5.6 \%) \text { at } 24 \\
\text { h0 3(52.9\%) } \\
4 \sim 6(35.3 \%) \\
6<(11.8 \%) \\
\text { at from } 4 \text { to } 12.5 \\
\text { months. }\end{array}$ & $\begin{array}{l}\text { At least, } 4 \\
\text { month }\end{array}$ & $\begin{array}{l}\text { No procedure } \\
\text { related } \\
\text { complication }\end{array}$ \\
\hline
\end{tabular}

GRNB: Gray ramus nerve block, RF: radiofrequency, VAS: visual analog scale, E-G-F-P: excellent-good-fair-poor, TL: thoracolumbar, ODI: Oswestry Low Back Disability, RDQ: Roland-Morris Disability.

The strength of our study is that the same treatment protocol for acute fractures was applied to all patients. The treatment effect was recorded through the same questionnaire survey at pre-procedure and on the 3rd, 14th, 30th, 90th, and 180th days after the GRNB block, allowing us to evaluate the effect over time. Our study's other strength is that we define the treatment failure group and analyze the risk factors in this group.

A limitation of our study is that it was a retrospective study, and there was no control group. Compared to conservative treatment alone or shame procedure or cement augmented procedure such as vertebroplasty or kyphoplasty, we may identify the effective time point and period compared to control group. And without a control group, the effect of GRNB may be minimal clinical differences. Another limitation is that the acting time of the drugs used in the block is short acting agent. Various block regimens, such as triamcinolone and RF, were used in other studies. To date, there have been no studies on the difference between these drugs. If a paper that addresses these problems is published in the future, it is believed that a reliable verification of the effect of GRNB treatment will be possible. The other limitation is that, radiologic factors such as changes in the morphology of fractures have not been analyzed as risk factors for treatment failure. The kyphotic angular change of the patient's body shape due to fractures over time may affect treatment failure.

\section{Conclusions}

The GRNB could relieve acute pain and improve quality of life. The motion pain decreased rapidly for three days and was maintained for 90 days after the procedure. Decreased BMD is a risk factor for GRNB treatment failure. 
Author Contributions: Conceptualization and planning, T.-G.K. and I.C.; methodology, I.C., D.-Y.P. and W.-J.K.; validation and data analysis, I.C. and D.-Y.P.; interpretation of the results, I.C. and D.-Y.P.; original draft, writing, review, and edit, I.C., E.-K.K., I.-Y.S., D.-Y.P. and I.C. All authors have read and agreed to the published version of the manuscript.

Funding: This research was funded by Hallym University Research Fund 2016 (HURF-2016-35).

Institutional Review Board Statement: The study was conducted according to the guidelines of the Declaration of Helsinki, and approved by the Institutional Review Board of HALLYM UNIVERSITY (protocol code 2021-03-011) on 31 May 2021.

Informed Consent Statement: Our study was a retrospective study and informed consent was waived. This has been approved by the IRB.

Acknowledgments: The authors thank Ah Young Yoon for drawing the Figure 3.

Conflicts of Interest: The authors declare no conflict of interest. The funders had no role in the design of the study; in the collection, analyses, or interpretation of data; in the writing of the manuscript, or in the decision to publish the results.

\section{References}

1. Melton, L.J., III; Thamer, M.; Ray, N.F.; Chan, J.K.; Chesnut, C.H., III; Einhorn, T.A.; Johnston, C.C.; Raisz, L.G.; Silverman, S.L.; Siris, E.S. Fractures attributable to osteoporosis: Report from the National Osteoporosis Foundation. J. Bone Miner. Res. 1997, 12, 16-23. [CrossRef] [PubMed]

2. Clynes, M.A.; Harvey, N.C.; Curtis, E.M.; Fuggle, N.R.; Dennison, E.M.; Cooper, C. The epidemiology of osteoporosis. Br. Med. Bull. 2020, 133, 105-117. [CrossRef] [PubMed]

3. Szulc, P. Vertebral Fracture: Diagnostic Difficulties of a Major Medical Problem. J. Bone Miner. Res. 2018, 33, 553-559. [CrossRef] [PubMed]

4. Ballane, G.; Cauley, J.A.; Luckey, M.M.; Fuleihan, G.E.H. Worldwide prevalence and incidence of osteoporotic vertebral fractures. Osteoporos. Int. 2017, 28, 1531-1542. [CrossRef] [PubMed]

5. Kanis, J. The burden of osteoporosis. J. Endocrinol. Investig. 1999, 22, 583-588. [CrossRef] [PubMed]

6. Buchbinder, R.; Osborne, R.H.; Ebeling, P.R.; Wark, J.D.; Mitchell, P.; Wriedt, C.; Graves, S.; Staples, M.P.; Murphy, B. A randomized trial of vertebroplasty for painful osteoporotic vertebral fractures. N. Engl. J. Med. 2009, 361, 557-568. [CrossRef] [PubMed]

7. Lieberman, I.; Dudeney, S.; Reinhardt, M.-K.; Bell, G. Initial outcome and efficacy of "kyphoplasty" in the treatment of painful osteoporotic vertebral compression fractures. Spine 2001, 26, 1631-1637. [CrossRef] [PubMed]

8. Watts, N.B.; Harris, S.; Genant, H.K. Treatment of painful osteoporotic vertebral fractures with percutaneous vertebroplasty or kyphoplasty. Osteoporos. Int. 2001, 12, 429-437. [CrossRef] [PubMed]

9. Stevenson, M.; Gomersall, T.; Lloyd Jones, M.; Rawdin, A.; Hernández, M.; Dias, S.; Wilson, D.; Rees, A. Percutaneous vertebroplasty and percutaneous balloon kyphoplasty for the treatment of osteoporotic vertebral fractures: A systematic review and cost-effectiveness analysis. Health Technol. Assess. 2014, 18, 1-290. [CrossRef] [PubMed]

10. Kim, S.W.; Ju, C.I.; Lee, S.M.; Shin, H. Radiofrequency Neurotomy of the Gray Ramus Communicans for Lumbar Osteoporotic Compression Fracture. J. Korean Neurosurg. Soc. 2007, 41, 7-10.

11. Jang, J.S.; Kwon, H.K.; Lee, J.J.; Hwang, S.M.; Lim, S.Y. Rami communicans nerve block for the treatment of symptomatic schmorl's nodes-A case report. Korean J. Pain 2010, 23, 262. [CrossRef]

12. Chandler, G.; Dalley, G.; Hemmer, J.; Seely, T. Gray ramus communicans nerve block: Novel treatment approach for painful osteoporotic vertebral compression fracture. South. Med. J. 2001, 94, 387-393. [CrossRef] [PubMed]

13. Suseki, K.; Takahashi, Y.; Takahashi, K.; Chiba, T.; Yamagata, M.; Moriya, H. Sensory nerve fibres from lumbar intervertebral discs pass through rami communicantes: A possible pathway for discogenic low back pain. J. Bone Jt. Surg. Br. Vol. 1998, 80, 737-742. [CrossRef]

14. Vanaclocha, V.; Saiz Sapena, N.; Rivera, M.; Herrera, J.M.; Ortiz-Criado, J.M.; Monzó-Blasco, A.; Guijarro-Jorge, R.; Vanaclocha, L. Selective block of grey communicantes in upper thoracic sympathectomy. A feasibility study on human cadaveric specimens. Br. J. Neurosurg. 2020, 34, 362-369. [CrossRef]

15. Tae, H.S.; Kim, S.D.; Park, J.Y.; Kim, S.H.; Lim, D.J.; Suh, J.K. Gray ramus communicans nerve block: A useful therapeutic adjuvant for painful osteoporotic vertebral compression fracture. J. Korean Neurosurg. Soc. 2003, 34, 505-508.

16. Chandler, G.; Dalley, G.; Hemmer, J.; Seely, T. Comparison of Thoracic versus Lumbar Gray Ramus Communicans Nerve Block in the treatment of painful osteoporotic vertebral compression fracture. Pain Physician 2000, 3, 240. [CrossRef]

17. Choi, S.E.; Suh, J.W.; Hwang, S.M.; Lim, S.Y.; Shin, K.M. Clinical Efficacy of Ramus Communicans Nerve Block in Patient with Vertebral Compression Fracture. J. Korean Pain Soc. 2004, 17, 175-179. [CrossRef] 